\title{
How Middle-Class Parents Help their Children Obtain an Advantaged Qualification: A Study of Strategies of Teachers and Managers for their Children's Education in Hong Kong before the 1997 Handover
}

\author{
by Yi-Lee Wong \\ Tohoku University \\ Sociological Research Online 12(6)5 \\ <http://www. socresonline.org.uk/12/6/5.html> \\ doi:10.5153/sro. 1638
}

Received: 9 Jul 2007 Accepted: 18 Oct 2007 Published: 30 Nov 2007

\begin{abstract}
It is well-documented for most industrial-capitalist societies that despite educational expansion, class differentials in educational attainment persist. This paper seeks to understand mechanisms maintaining the class differentials by examining how two groups of middle-class parents - teachers and managers - help their children obtain an advantaged qualification. Qualitative data were collected in Hong Kong between 1996 and 1997. Given a changing employment structure, teachers and managers anticipated that their children would need at least a bachelor's degree in order not to become disadvantaged in the future labour market and therefore used economic, cultural, and social resources to enable their children to obtain such a qualification. However, despite their strategies, whether respondents will succeed in achieving that remains uncertain. In addition, the evidence also indicated that their strategies could be counterproductive. This points to a need for researching into possible negative impacts of strategies of middleclass parents on their children's academic performance and emotion. As Hong Kong is then under the Chinese rule after the 1997 handover, this study documenting strategies of middle-class parents for their children's education under the British rule could serve as a reference for future comparisons.
\end{abstract}

\section{Keywords: Aspirations; Education; Middle Class; Hong Kong; Resources; Strategies}

\section{Introduction}

1.1 The last century has seen an introduction of free basic education and educational expansion at all levels in many industrial-capitalist societies (e.g. Schofer and Meyer 2005). In absolute terms, the numbers of people who obtain a basic education and a higher education have been increasing. However, while celebrating this improvement, sociologists direct our attention to the relative aspect. As shown in Shavit and Blossfeld's (1993) classic collection of studies on educational inequality covering a range of thirteen industrial-capitalist societies, despite educational expansion, class differentials in educational attainment persist. While there is disagreement over whether this class gap has been narrowed or widened (e.g. Moore 2004 and the recent literature cited therein) and how the class gap should be interpreted (e.g. Marshall et al. 1997; Saunders 2002), most sociologists would agree that an expansion of education does not necessarily lead to an equalisation of the distribution of education. In fact, educational expansion seems to benefit more children of advantaged class origins, ${ }^{[1]}$ usually labelled as the middle class, than their disadvantaged-class counterparts, labelled as the working class. How, then, is stability possible in the context of change (e.g. Devine 1998)? Over the past few decades, a considerable number of studies have sought to explain the persistence of this class gap. A two-stage mechanism advanced by Halsey and his associates (1980) is a well-known attempt: they argue that during the first stage of an educational expansion, middle-class children rush in to occupy new places created by the expansion; and then, during the second stage, when there is saturation working-class children start to fill up the remaining places. This mechanism is echoed by Raftery and Hout's (1993) hypothesis of maximally maintained inequality. The explanation offered by Halsey and his associates is consistent with a common assumption that people of advantaged classes are interested to preserve their advantages over generations. Their explanation, however, does not tell us what mechanisms are at work so that more middle-class children than workingclass children are capable of taking advantage of educational expansion filling up the new places created. 
Appealing to biology, some (e.g. Saunders 1995; cf. Herrnstein and Murray 1994 ${ }^{[2]}$ ) claim that this is because middle-class children are born to be more intelligent than their working-class counterparts. But, this claim has been discredited by many studies showing that academic ability alone does not explain the class gap (e.g. Savage and Egerton 1997). ${ }^{[3]}$ Examining the operation of the education system, ${ }^{[4]}$ some scholars put forward several mechanisms, albeit controversial and remaining debatable: tracking, streaming, teacher's self-fulfilling prophecies, and interactions between teachers and students in classroom (e.g. Willis 1977; Bernstein 1993; cf. Foster et al. 1996). Comparatively speaking, what happens within the family still remains as a black box. Over the years class differences in resources (see the collection in Morgan et al. 2006 and the recent literatures cited therein) and class differences in culture, values, beliefs, and educational aspirations (e.g. Lewis 1959; Kohn 1977; cf. Bourdieu and Passeron 1977) have been demonstrated. But what is crucial is to illustrate how class differences in aspirations and/or resources are converted to class differentials in educational attainment. Sociologists have been focussing on what the working class lack and absorbed into debating over whether the class differentials are explained by material deprivation - the working class lacking the required resources - or cultural deprivation - the working class lacking educational aspirations or a so-called 'proper' culture to appreciate the importance of education. [5] This debate is important because that would lead to rather different social policies if this class gap is to be narrowed: whether to provide the working class with extra material support or to compensate them with a culture which would make them aspire to education. [6] Perhaps the idea of cultural deprivation risks being accused of blaming the working class, so some sociologists want to explain the persistence of the class gap without recourse to the cultural dimension altogether. Referring to the notion of secondary effects of social stratification, Boudon (1974) argues that class background shapes not only children's economic resources received from their parents, but also children's educational aspirations. In deciding whether to continue to stay on in education, students, assumed as rational beings, are making choices based on sets of costs and benefits that reflect their class situations (e.g. Breen and Goldthorpe 1997; cf. Nash 2006). In this sense, referring to material conditions alone, without invoking any elements of culture, is enough to capture class differences in both economic and cultural aspects in explaining the class gap (cf. Goldthorpe and McKnight 2006). Nevertheless, rational choice approach, while recognising the agency of individuals, seems inadequate in regard to understanding how individuals make choices in two senses. First, as Savage (2000) quite rightly argues, rational choices are not made in a social vacuum but within a cultural framework: whether a decision is considered to be rational is contingent on its context and cultural framework (cf. Skeggs 1997; Devine and Savage 2000). Second, as Ball and his associates (2000) illustrate, not all individuals as actors are good planners or take education in the same instrumental way; the principles of leisure and pleasure could come into play in governing how individuals make decisions.

1.2 With a view to understanding why the middle class are more capable than their working-class counterparts of taking advantage of educational expansion, it is certainly important to know what the working class lack. But it is equally important to know the other side of the story: what the middle class do with what they have so as to understand why they have been successful in preserving their interests, namely, strategies of the middle class for their children's education. And, instead of indulging in debating over whether resources or aspirations count more, it seems more useful to focus on both resources and aspirations. That is, we identify educational aspirations of middle-class parents for their children and then examine how the parents, in view of options available in institutional settings of a particular context, use resources and formulate strategies to realise their aspirations for their children (cf. Erikson and Goldthorpe 1992). Three types of resources are distinguished: economic, cultural, and social resources (cf. Treiman and Yip 1989). ${ }^{[7]}$ Generally speaking, economic resources refers to capital in various forms, flow of income, and availability of credit; cultural resources refers to formal qualifications, skills, aspirations for children's future, and possession of relevant information such as how the educational system and the social system work in society; and, social resources refers to social networks and connections. In order to understand better how parents' educational aspirations and resources are converted to their children's education (e.g. Lynch and Moran 2006), textured analyses and contextualised evidence are required. The insights on this topic have been from evidence about the West in general and Britain in particular; would they still apply in the case of Hong Kong? This paper seeks to take up this endeavour examining strategies of Hong Kong middle-class parents for their children's education. In what follows, I shall first provide the background of this study and then report on how teachers and managers in Hong Kong before the handover of its sovereignty to China in 1997 helped their children obtain an advantaged qualification.

\section{Research design}

2.1 This is a qualitative study on strategies of teachers and managers - two occupational groups of Goldthorpe's (Erikson and Goldthorpe 1992: 39-42) service-class professional and managerial employees for their children's education in Hong Kong before the 1997 handover. [8] Hong Kong is an industrialcapitalist society and the class gap found in many industrial-capitalist societies is also observed for Hong Kong (cf. Chan 1994); so it could be used as an example to illustrate mechanisms through which class differentials in educational attainment persist. Teachers and managers are selected because unlike many specific middle-class occupations which could only be found in Class I or Class II of Goldthorpe class scheme, such as lawyers (Class I) or social workers (Class II), they are two rather broad categories covering a wider range of occupations from both Class I (lecturers at university or CEOs in an international corporation) and Class II (teachers in primary school or managers in a small firm); their experiences can perhaps be used to represent the general experience of the middle class (Classes I and II). From 1978 onwards, children in Hong Kong begin their formal education at the age of six. In order to obtain concrete illustrations of what respondents have done for their children's education, I recruited managers or teachers who had at least one child aged six or above and then interviewed them as well as their spouses, if the spouses agreed. 
2.2 Having set the selection criteria, I recruited eighty-nine respondents, parents of forty-nine families: forty-three teachers $(T)$, thirty managers $(M)$, and sixteen spouses who were neither teachers nor managers. ${ }^{[9]}$ Three respondents (parents of two families) were recruited through formal channels. ${ }^{[10]}$ Most respondents were recruited informally through the use of my social networks. Initially I contacted my former-teachers, parents of former-schoolmates, and parents of former-students whom I gave private tutorials so as to invite them to join this study. However, I suspected that my class and demographic background made the recruitment rather difficult: coming from an urban poor family, as a young and single $\mathrm{PhD}$ student at the time, I did not know many middle-class parents who had at least a child aged six or above. ${ }^{[11]}$ So, I had to be thick-skinned to contact even acquaintances I met when I did my bachelor's and master's degrees at a local elite university so as to use their social networks for recruitment. That is, apart from exploiting directly my own social networks, I also used as much as possible the social networks of my relatives, friends, and acquaintances to recruit people who met my set criteria. I then asked the interviewed respondents to introduce me to further qualified respondents; but this snowballing process was not very successful: only four more respondents (parents of two families) were recruited.

2.3 Respondents were interviewed between September 1996 and August 1997. [12] The interviews were taped, which ranged from forty-five minutes to two-and-half hours (the average being an hour); they were then transcribed and translated from Cantonese, the major local dialect in Hong Kong, to English. For present purposes, I shall mainly report on what respondents have done for their children's education. On average the respondents were aged about forty-four (in 1997), ranging from thirty-eight to fifty-nine years of age. Sixty of them were born in Hong Kong, whereas the remaining twenty-nine were not and most of them were born in China. The majority of my respondents were brought up in Hong Kong and received at least a local senior secondary education; as I shall mention below, this qualification led most of them to a relatively advantaged well-paid occupation. Respondents had on average two children, ranging from one to three. The average age of the children is about fourteen years old, ranging from one year old to twentynine. Amongst ninety-eight children, most of them were still at school and only seven children completed education and were working.

2.4 This is a retrospective study of a small non-random sample of self-selected middle-class parents, implying that there are two major limitations. First, my respondents were asked to look back on what they did before; their accounts were unavoidably partial in that they may fail to recall accurately what happened in the past or they may even select apposite episodes to rationalise what they did (cf. Elder 1981). Second, my respondents were recruited basically through my social networks, although they had to meet the set criteria; their accounts could not be used to make statistical generalisations. Readers should bear these limitations in mind in interpreting respondents' accounts; but, these limitations, I believe, do not make their accounts, however partial and however statistically unrepresentative, less useful in illustrating how middle-class parents help their children obtain an advantaged qualification.

\section{Aspirations, resources, and strategies}

3.1 My respondents were growing up in Hong Kong in the 1950s and 1960s when it was poor and underdeveloped in many aspects (Hambro 1955). They witnessed how Hong Kong experienced a compressed development changing from a fishing village to a cosmopolitan city in a few decades. ${ }^{[13]}$ Industrialisation did not start until the 1950s; this led to an expansion of the manufacturing sector bringing abundant employment opportunities in the 1960s and 1970s: over $40 \%$ of the working population were employed in that sector. From the 1970s onwards, the manufacturing sector has been in decline, consisting of less than $20 \%$ of the working population in 1996, while the service sector has expanded rapidly. In particular, the proportion of working population having a professional, administrative, or managerial job was increased from $8.2 \%$ in 1961 to $29.2 \%$ in 1996. However, the development of social support in Hong Kong did not keep pace with its economic growth. For example, child labour was not uncommon; the law setting the minimum legal age at fifteen for all kinds of employment came into effect only in 1980 (Hong Kong 1981: A Review of 1980). Yet, the government played a strong role in education. The provision of education in Hong Kong from primary form one onwards has been solely decided by the government (Post 1993). The last five decades have seen two major improvements. First, basic education has become free, universal, and compulsory: the acts of free, universal, and compulsory six-year and nineyear education were passed in 1971 and 1978 respectively. Second, the education system could be seen as moving from very elitist on the way to a mass education system. There was only one university before 1963 ; less than $4 \%$ of the population aged fifteen or above had a tertiary education and only about onetenth completed a secondary education in the early 1970s. In contrast, the number of university rose dramatically from two to seven in 1992; the proportion of the population aged fifteen or above receiving a tertiary education was increased to about $15 \%$ and nearly half completed a secondary education around the mid-1990s.

3.2 There were also changes in class structure. In early Hong Kong, there were three main strata: the British ruling class at the top and the mass Chinese at the bottom, mediating by a small number of local Chinese elites who were bilinguals helping the ruling class rule the colony (cf. Chan 1991). In addition to economic development, the colonial Hong Kong British government also played a part in contributing to the changes in the employment structure: they made some positions, especially junior ones, in the bureaucracy of civil service open to local Chinese people. With a senior secondary education in the 1960s and 1970s, people were already relatively advantaged (Chan 1994) having at least three paths available leading them, immediately or eventually, into the middle class: a professional path, taking up such a lowerlevel professional job as nurse, school teacher, or social worker; a bureaucratic path, starting as a junior civil servant and getting promoted to become an administrator within the bureaucracy of civil service; and a managerial path, beginning as a junior clerk in an international corporation and getting promoted to become a manager in the private sector. Even without such qualification, it was still possible to get into the middle class, as in the cases of Mr. Wan ${ }^{[14]}(\mathrm{M})$ and Mr. Kwok (M). Against this context, Goldthorpe's service- 
class professional and managerial employees became socially visible in Hong Kong of the early 1980s. It remains debatable whether a Hong Kong middle class with its distinctive practices, values, or attitudes is therefore formed. But, this group of professional and managerial employees was generally seen as the first-generation local middle class in that they were the first-generation taking up relatively advantaged economic and social positions vis-à-vis the general population (cf. Lui 1998). My respondents are one of them.

3.3 In stark contrast to the situation in the 1960s and 1970s, many systems became more developed and institutions more established in the 1980s and 1990s; entry requirements in terms of formal qualifications for all kinds of jobs were raised. In the mid-1990s, it was not surprising to find that people even with a bachelor's degree could land on only a clerical job, with poorer career prospects than a post of a similar title in the 1970s. My respondents realised that the way of getting into the middle class was becoming more standardised for their children, namely, through formal qualification. When asked about aspirations for their children, all respondents wanted their children to have at least a bachelor's degree; except for four managers who wanted their children to make a career in the private sector or have their own business, the others all wanted their children to become professionals such as doctor or lawyer or engineer. It remains unclear to what extent their educational aspiration could be explained by Mare and Chang's (2006) thesis of baseline expectation - parents using their own educational attainment as a baseline and expecting their children to obtain a qualification higher than this baseline - and to what extent it could be explained by the possibility that respondents value intrinsically a university education. But what is clear is this: my respondents have such aspirations for their children because they anticipate that this qualification will be a necessity for their children to secure a promising future. Mr. Law's (M) articulation is a typical example:

I will be happy if my children want to go further than a bachelor's degree. Of course I want them to become engineers or doctors. In a word, professionals. (...) Their time will be different from mine: social competition is getting more and more severe. A secondary education is no more a guarantee of getting a good job. (...) If they are professionals, they will hardly have any problems in getting a promising job anywhere.

3.4 Promoting the educational success of one's children involves using resources and strategies in three broad areas: giving their children a head start, ensuring that they perform well enough to get promoted to the next level, and arranging remedial plans in case they fail to get to the next level. Now let me turn to how respondents have used their resources and strategies in these three areas to help their children obtain at least a bachelor's degree.

\section{Giving their children a head start in the education system}

3.5 In giving their children a head start in education, all respondents, as with other parents, had to let their children join a centralised allocation scheme: Primary One Admission System (POAS). This system, introduced in 1983, was for all children aged six (e.g. Sweeting 2004). Joining POAS was the beginning of each child in Hong Kong receiving a universal, free, and compulsory nine-year education. While parents could still apply separately on their children's behalf to individual primary schools, they are asked to opt for one school for them through POAS. Then children will gain points according to some criteria; the following criteria gain them most points: their family is living in the same district (school zone) as the school applied; one elder sibling is studying there at the time of application; one parent is currently working there; and, one parent is an alumnus or alumna of the school applied. The more points they gain, the more likely children are to be assigned to the school that their parents have opted for. If children cannot get into the one that their parents have chosen, they will then be randomly allocated to a primary school.

3.6 As with their western counterparts, my respondents responded rather strategically to meet the requirements set by the education system: they mobilised their resources in order to make their children advantaged in POAS. Consistent with Coleman's (1988) finding, all respondents were using their social resources - social connections like friends and colleagues - to solicit information about the ranking and characteristics of primary schools, as in the case of Mrs. Chee (S/T):

Initially I chose school A for my elder daughter. But a close friend of mine told me that the ranking of school A was then lower than before. (...) And it was not as good as I had thought. So, following her suggestion, I applied to school B, instead of school A, for my elder daughter.

3.7 Knowing the ranking and characteristics of schools, however, was not necessarily enough for respondents to reach a decision for their children. Respondents' cultural resources also played a role: what they considered to be good for their children in the context of Hong Kong. Mrs. Tung (M) articulated her concern:

My husband and I could not really decide as to sending our daughters to what kind of primary school. We could go for either a brand-name primary school with a good academic reputation, or an ordinary one upholding balanced teaching philosophies. The latter takes care of all aspects of a child's development, whereas the former directs most attention to a child's intellectual development at the expense of other areas. Obviously, a brand-name primary school is more likely than an ordinary one to lead my daughter to an elite secondary school and thus a more promising educational career. However, I am sure my daughter will be happier if she studies in an ordinary primary school, which provides her with a balanced development.

3.8 Unlike Mrs. Tung (M), most respondents did not have this kind of struggle but clearly wanted their 
children to get into an elite primary school because they saw it as a head start. One could argue that the local circuits of schooling proposed by Ball (e.g. 2003) are also found for Hong Kong: the targets of my respondents were only a number of elite primary schools. Most respondents, teachers or managers, used their resources to work POAS in the hope that heir children could get into a school of their choice through POAS. Unsurprisingly, social resources of teachers, especially those teaching in elite schools, through work - as in the cases of Mrs. Au (T) and Mrs. To (T) - and alumni's social resources through old boys or girls networks - as in the cases of Mr. Mo (M), Mrs. Mo (T), Mr. Pak (M), and Mr. Pak (T) - benefited their children directly from POAS. Their economic resources were also relevant in the case of Mr. Au (M) and Mrs. Au (T): similar to their British counterparts, they bought an expensive apartment in a 'school zone' with many elite schools - a 'good' catchment area - because they wanted to get their younger daughter into another elite school through POAS (cf. Bulter and Robson 2003). This strategy was relevant in Britain and Hong Kong, and it is still highly relevant in nowadays Hong Kong. ${ }^{[15]}$ Even when their children failed to get into the school of their choice through POAS, social connections of respondents would then be exploited so that their children would at least get into another elite school. While teachers usually have more relevant social connections than most managers in this regard, it does not mean that managers are doomed to be disadvantaged, as in the case of Mr. Fan (M). After getting the POAS result that his elder daughter did not get assigned to the school of his choice, he immediately called his friend who knew the principal of another elite school so as to arrange an interview for her.

\section{Ensuring that their children perform well in the education system}

3.9 Having a head start did not mean that children would perform well at school. It is well known that the education system in Hong Kong is very selective full of many school examinations and public examinations. The following two are now the most important public examinations: Hong Kong Certificate of Education Examination (HKCEE) taken at the age of sixteen ${ }^{[16]}$ and Hong Kong Advanced Level Examination (HKALE) taken at the age of eighteen. [17] While about $6-8 \%$ of the population of the relevant age group could get into a local university in the 1980s and 1990s, the government decided to increase the proportion to 16-18\% in 1995 and maintained it at that level since then. In order to enable their children to perform well at school and in the public examinations and ultimately to get a university education, respondents in thirty-four families helped with their children's school work, and respondents of thirteen families employed private tutors for them. Perhaps it is not so surprising when compared with their western counterparts in this regard. But unlike their western counterparts, many respondents sent their children to cram schools. In fact, children, of all classes alike, are attending cram schools and the business of cram schools could be compared to a shadow education. This situation is also found in Japan, South Korea, and Taiwan (cf. Bray and Kwok 2003). It may be interesting to investigate whether this practice is more specific to the competitive education system, relative to the US system for example, found in these East Asian societies all strongly influenced by Confucianism.

3.10 Having good academic results, however, is not necessarily sufficient for securing a place in an elite secondary school or a university. Teachers and managers realised that in deciding whether to give a place to a student, elite secondary schools and universities would also consider the student's participation and performances in extra-curricular activities. The fees of joining these activities were usually high. Yet, choosing what activities for their children required not only respondents' economic resources but also cultural and social resources. In arranging extra-curricular activities for their children, respondents chose activities that counted in the education system; they solicited information from their relatives, friends, and colleagues to check whether their choices were 'correct' and they also asked them to recommend good classes or coaches for their children. Indeed, the children of respondents participated considerably in a range of extracurricular activities. ${ }^{[18]}$ The most popular activities were learning to play various kinds of musical instruments, especially the piano ${ }^{[19]}$ and violin, attending art lessons, and taking sports such as swimming and ball games. While it is prestigious for Lareau's (2000) respondents to send their children to learn French in the US, both teachers and managers were keen for their children to learn English and Putonghau. ${ }^{[20]}$ They paid for their children's expensive one-to-one language classes taught by native speakers. While ability to speak fluent English has been an advantage for getting a well-paid job in Hong Kong, people anticipate that ability to speak fluent Putonghau will confer advantages after the handover to China. In addition, the respondents also encouraged their children to join inter-school competitions because getting a certificate of participation in an inter-school competition, let alone awards or medals, would increase their chances of getting into an elite secondary school or a university. But, respondents' cultural resources could also be relevant: what qualities of an individual they consider to be desirable and what extra-curricular activities they think would allow their children to acquire such qualities. Most respondents, managers and teachers alike, believed that their children have to acquire qualities such as self-discipline, diligence, perseverance, and ability to defer gratification (cf. Devine 2004: chapter 5), which would in turn contribute to their children's future success, as Mr. Fan (M) articulated:

I don't want my daughters to hang around and do nothing. (...) They should do their best but not muddle along. (...) I want them to be serious and persevering. They should understand that if they want to be successful, they should make an effort. That's why I train them to compete in an Inter-school Speech Festival every year. Actually I want to train their confidence and perseverance.

3.11 What is difficult here is how we should make sense of Mr. Fan's (M) beliefs. On one level, it remains unclear to what extent we can say that Mr. Fan (M) holds so-called middle-class values, in Bourdieu's sense or in a sense used for the middle class in the West, demarcating him from the working class, because these values could very well be seen as so-called Chinese values held by the Chinese of all classes. But, what is clear is that these values are rewarded at school. So, on another level, it is difficult to tease out if Mr. Fan (M) holds such values because he genuinely believes that these qualities are 
intrinsically good or because he knows that his daughters behaving that way would get rewarded at school. Nonetheless, the point is that both managers and teachers know how to work the system. How well they could work the system requires cultural resources not only in terms of their awareness of what extracurricular activities counted and what qualities were rewarded in the education system, but also in terms of their knowledge about which subjects would be marketable in the context of Hong Kong. Mrs. Chin's $(T)$ rationale behind her advice for her daughter was an illustration of this:

My daughter had been the top student and was allowed to choose any stream. ${ }^{[21]}$ She said she was interested in arts. But I analysed for her that she might read the literature she liked in her spare time; however, if she took science, she would have more subject choices for higher education and job choices. Finally she chose science. (...) I also advised on her subject choices at university. She wanted to choose Philosophy. But I suggested that she had better consider her job choices in choosing subjects for her first degree - she had to be practical; after all she need to think about her career first. And she could choose Philosophy for a second degree if she was really keen on it. So finally she chose Economics.

3.12 While it remained unclear whether Mrs. Chin valued intrinsically science stream in secondary school or Economics at university, it seemed quite clear that she was aware that these were popular options for top students in Hong Kong. It seems that in choosing a subject to major at university, their children's interests are of secondary importance to my respondents: their most fundamental concern is about whether the subjects chosen for their children will be marketable conferring advantages in the future labour market. It is argued that what distinguishes middle-class parents from their working-class counterparts, in Britain at least, is that most middle-class parents value education highly, especially its intrinsic values, whereas most working-class parents do not but are taking education rather instrumentally. However, apparently, most of my respondents, teachers or managers, as just quoted above from Mr. Fan (M) and Mrs. Chin $(T)$, are very instrumental towards their children's education, whereas only very few of them expressed how they valued the intrinsic values of education. This seems to pose a challenge to our conventional understanding of the middle class derived from studies about the West. Three plausible interpretations could be advanced. First, this finding implies that my respondents as first-generation local middle-class members are holding a middle-class position but not middle-class values or attitudes portrayed for their western counterparts; the Hong Kong first-generation middle class have yet developed any local middle-class values or culture (including in Bourdieu's sense of habitus). Second, this finding shows that this instrumental attitude towards education is culturally specific to the Hong Kong middle class. Or, third, this finding suggests that the distinction between the middle class and the working class is actually not that sharp. In short, more comparative work is required in order to see which interpretation is the case.

3.13 Apart from choosing for their children marketable subjects, respondents were also concerned about the choice of university. As many respondents articulated, when there are more places at tertiary institutions, competition is not simply about getting a diploma, but which diploma (in what subject awarded by which institution). So, when there are more local universities and the option of overseas universities becomes more available, some respondents are primarily concerned with not a university education, but which university education (Reay et al. 2001; cf. Brown and Scase 1994). Mr. Ming's (M) concern of getting his daughter into a more prestigious university was an example:

My younger daughter had excellent HKCEE results: seven As and two Bs. (...) With this result, she could excel anywhere. And I don't think she should confine herself to the University of Hong Kong. (...) I sent her to a college in New York, which was a gateway to take her a more prestigious university there. (...) I was actually thinking about Cornell, Yale, and Harvard. (...) Finally, she decided to go to Cornell. (...) I even flew over with her and took her to the university. I rented a house and a car for her, and gave her a monthly stipend.

3.14 Cost was simply not a problem for Mr. Ming (M) and the University of Hong Kong, one of the two local universities at the time, was also not good enough for his daughter. Having a similar concern, Mr. Kwong (T) sent his children to London School of Economics in Britain and Mr. Lung (T) sent his son to Yale in the USA. As mentioned above, places in local higher education were extremely limited in the past; the general perception was that only those who could not secure a place in one of the two local universities or those exceptionally rich would study abroad for a degree. When more places in local universities have become available, more and more middle-class parents, like my respondents, are sending their children abroad probably because they are concerned that the global rankings of the local universities are not high enough (e.g. Post 1994; cf. Morris et al. 1994). If the local circuits of schooling (cf. Ball 2003) are found for middleclass children in Britain, perhaps we should examine further to see if a global circuit of schooling could be identified for their Hong Kong counterparts, against the context of a growing international or global educational market in which more and more rich middle-class parents in East Asia are sending their children to the West for a higher education (cf. Waters 2006).

\section{Arranging remedial plans for their children}

3.15 However, not every child performed so well. Many teachers and managers, as with their western counterparts, expressed that they were prepared to pay for their children's examination re-sits in case the children failed. One may suspect that teachers would and could be more strategic than managers because they should know the education system better and have more relevant social connections. The truth is that managers are no less well-informed about how to work the system or no less capable of helping their academically-less-capable children, as it is the case when what Mrs. Choi (T) and Mr. Cha (M) did for their children are compared. And, Mr. Yu (M) could even be seen as one of the most strategic: his plans were very telling about how well-informed he was about the system and how well he could work the system so 
The results of HKCEE and General Certificate of Secondary Education (GSCE) in Britain are both recognised as O-level results in Hong Kong. But examination papers for GCSE are much easier than those for HKCEE. I thought to myself 'why don't I give my children one more, better, chance to get better grades which have the same recognition in Hong Kong?' In fact, even if they did not do so well in both examinations, I could still fly them to Britain to take another GSCE there, because the examination was held a bit later than that held in Hong Kong. (...) My children did not do very badly in HKALE. But there were only two universities in the early 1990s; and they could not get a place in either. (...) I sent my daughter to London School of Economics in Britain. I think this option is no worse than a local university.

3.16 If letting their children take a re-sit or sending them to study in an overseas university when they failed to secure a place in the local education system is considered to be remedial, then sending them abroad at a pre-university stage so as to by-pass local severe competition could be seen as preventive. This option is costly but is particularly attractive to children who are unable to meet the local requirements, because the educational environment abroad is often seen as less stressful and competitive so that children are believed to be more likely to obtain a higher level of qualification there. Mr. Wan (M) recalled his considerations in taking this option for his son:

We sent our son to Canada after he completed secondary form three. (...) My wife said our son's academic results were just so-so in Hong Kong. Perhaps it would be better to let him study in a less competitive environment such as Canada. (...) We were actually considering Australia, Britain, Canada, and the USA. I heard from several friends that academic work was quite difficult in Britain and it was far too easy in Australia. And, some relatives and close friends reminded us that there were drug and gun problems in the USA. (...) Anyway, my wife's sister was already settling in Canada, so we thought Canada would be our best choice.

3.17 The decision of Mr. Wan (M) showed that taking this option involved not only economic resources supporting their son's studies abroad - but also cultural and social resources. Echoing Devine's finding (2004: chapter 7), in working the system, Mr. Wan (M) solicited information from people they trusted as a short cut in getting relevant information on countries under consideration in order to make an informed decision for their son. Sending their academically-less-capable children abroad in order to by-pass local severe competition perhaps could be seen as a feature distinguishing Hong Kong from its counterparts in the West. More comparative work is called for to see whether this is because the Hong Kong education system is much more competitive than those in the West, or because this fact itself reflects the global political relations between the developed and developing countries in that parents in Hong Kong, as with those in other developing countries, prefer to send their children to study in the developed countries.

\section{Conclusion}

4.1 This paper provides a textured analysis with contextualised evidence of how two groups of middleclass parents - teachers and managers - help their children obtain an advantaged qualification in Hong Kong, before the handover of its sovereignty of to China in 1997. And, as I show briefly elsewhere (Wong 2004), teachers and managers employ similar strategies and use resources in more or less the same way for their children's education. As with parents of advantaged classes throughout history, the respondents were also keen to preserve their interests over generations. In the context of contemporary industrialcapitalist society, they did it through getting their children an advantaged qualification. It remains unclear whether the respondents value education intrinsically; but evidently they see the instrumental values of education in social competition. As with their western counterparts, they are well aware that social competition is like positional competition (Hirsch 1995). Seeing educational expansion as signalling an increasing severity of social competition, my respondents believed that their children would need at least a bachelor's degree in order not to be disadvantaged in the future labour market. That is, applying Thurow's (1972) forceful argument advanced more than thirty years ago, we can say that respondents understand that a bachelor's degree does not in itself confer advantages in social competition; rather, children who do not have it will be disadvantaged as compared to those children who have. With a view to securing their children a bachelor's degree, my respondents were strategic in using economic, cultural, and social resources to work the education system. In order to give them a head start, the respondents created conditions that would make their children benefit from the education system, especially POAS, so that the children could get into an elite primary school. Then, the respondents provided their children with academic assistance, extra-curricular activities that counted in the system, and advice on choosing subjects which would lead them to a marketable degree in higher education so that the children would get into an elite secondary school, take advantaged subjects, and obtain good grades at school and in the public examinations. When their children got good grades, the respondents advised them further on choosing a marketable degree and even supported them doing it in a well-known university. Even when their children did not perform so well, the respondents supported them taking re-sits or helped them by-pass severe local competition. In brief, the evidence shows that middle-class children are advantaged because their parents could afford to provide them with the required resources, of all kinds, to work the system, including cultivating attitudes it rewards, rather than because their parents place emphasis on the intrinsic values of education. In this sense, we could well argue that middle-class children are advantaged vis-à-vis their working-class counterparts is due more to the fact that they are advantaged both materially and culturally in a strategic sense than to the view that they are advantaged culturally in the sense of Bourdieu's habitus. Yet, this finding could well result from a so-called sample bias or be due to the peculiarity of Hong Kong middle-class parents. Given that middle-class parents in the West are also reported to be equally instrumental vis-à-vis my respondents (e.g. Ball 2003), it would be desirable to conduct more comparative 
4.2 It is as yet too early to decide whether the strategies of my respondents for their children's education are successful, when most of their children are still at school. But, the available evidence indicated that some children failed to obtain a bachelor's degree or did not perform as well as the respondents had hoped. This is consistent with what Devine (2004) argues: whether the strategies of respondents will succeed involves a measure of indeterminacy. This is in line with the common view that the middle class are rather anxious and feel uncertain about whether they can successfully pass on their advantages to their children. This view has been reflected in a recent emphasis on risk and risk management in discussion over the social reproduction of advantages of the middle class (e.g. Ball 2003). Given that some respondents were very pushy, their academically-less-capable children might feel great pressure. But this pressure could be counter-productive. While I did not have much material on this from children's perspectives, Mrs. Chin's son ${ }^{[22]}$ could give us some ideas. Despite what his parents had done for his education, he failed HKCEE and took a re-sit once; because of this, he felt guilty about letting his parents down and did not have much confidence in passing HKALE. His sense of guilt echoes what Power et al. (2003) report in their longitudinal study on middle-class children in contemporary Britain. This seems to point to a need for exploring an under-researched area: possible negative impacts of pushy parents on their children academic performance and on the children's emotion such as feeling of guilt and academically inadequate and having low self-esteem.

4.3 In developing his theory of social mobility, Goldthorpe (2000) distinguishes strategies from above and strategies from below. He argues that the primary concern of every class is to stay where they are and after securing that they would seek to make further improvement. In the case of the middle class, these two concerns coincide and therefore their strategies from above are straightforward: securing a middleclass position. However, the working class' strategies from below are much less straightforward. Their primary concern is to maintain a working-class position; in seeking advancement, they might aim to obtain an intermediate class position rather than a middle-class one. This class difference in strategies then explains the class gap in educational and occupational attainments. But, the case of the Chinese might pose a challenge to Goldthorpe. The Chinese have a long history of using scholarship as a channel for upward mobility. And it is commonly believed that Chinese parents of all classes have the same desire of seeing their children obtain an advantaged qualification and are using similar strategies for their children's education. So, any layperson from Hong Kong might wonder whether the strategies of my respondents for their children's education are class specific in the context of Hong Kong or any Chinese societies. While it may well be true, I suspect that working-class parents would have more obstacles in using the same strategies for their children vis-à-vis their middle-class counterparts. ${ }^{[23]}$ Take the option of sending children to study in an overseas university as an example. It is difficult for working-class parents to acquire the required economic resources in order to take this option; but they could still overcome it, however difficult it would be, by making a loan, for example. But, I suspect that it would be much harder for them to acquire the required cultural and social resources: knowing the information about this option such as the ranking of universities in a particular country and the requirement and procedures of application for different universities, and knowing people from whom they could solicit relevant information relating to these issues. Everyone is supposed to be free to learn how to work the system or to make social contacts with anyone (cf. Bottero 2003). However, there are obstacles for the working-class parents to acquire such knowledge or to get to know the right contacts for the sake of their children's education. Without the required economic resources, the working class might still borrow them; but it is difficult to imagine how they could borrow the required cultural or social resources or find substitutes for them. Devine (2004) argues that against a changing context, it is no longer a straightforward affair for middle-class parents to secure their children an advantaged position in contemporary Britain. Perhaps it is also the case in Hong Kong. If so, we can expect that it would be even much more difficult for working-class parents to do the same.

4.4 I documented how middle-class parents in Hong Kong under the British rule sought to pass on their advantages to their children. Many parental strategies reported here are still relevant today under the Chinese rule after the handover, as indicated above; but changes are also observed. The following are some general impressions: parents' desire for their children to speak fluent English is as strong as that for them to speak fluent Putonghau; while it is still the case that many parents send their children to study abroad, the number of parents sending theirs to China to study is also on the rise. After the handover, Hong Kong experienced Asian financial crisis in 1997 and the crisis of SARS (severe acute respiratory syndrome) in 2003; the middle class seemed to suffer most: a lot of them had negative liabilities, if not going bankrupt, because of the collapse of the property market; and many of them, especially managers, lost their jobs. One may be curious to know how these changes impact on the middle class: for example, would the middle class become cynical about education and therefore opt for totally different strategies for their children? Although impressions from local journal reports do not support this suspicion but show that parents, all classes alike, become more and more anxious about their children's education, more work is definitely required to document what are the changes after the handover. My study could then serve as a reference for future comparisons. In conclusion, with a view to unpacking how class differentials in educational attainment persist against the context of change, more textured analyses in different industrialcapitalist societies are needed. And, until then we can also distinguish in what ways strategies of the middle class in Hong Kong are historical- or context- or cultural-specific and in what ways they could be seen as universal.

\section{Notes}

1 Class could be seen as one of the most notorious concepts in Sociology in that debates over how class should be defined, operationalised, or measured; which dimensions of class are most relevant in 
contemporary societies; and how we should approach class remain unsettled (for a useful summary and review, see Crompton 1998 and Savage 2000). By class, I do not mean in this paper to refer to individuals' subjective personal identification or their political consciousness; rather, taking class as a relational concept, I refer the middle class and the working class to the relatively advantaged and the relatively disadvantaged respectively.

${ }^{2}$ See Fischer et al. (1996) for a comprehensive critique of Herrnstein and Murray's bell curve.

${ }^{3}$ See a classic study in France by Schiff and Lewontin (1986) for a forceful critique on the irrelevance of intelligence quotient to educational attainment.

${ }^{4}$ See Moore (2004) for an elaborated treatment of approaches to educational inequality.

${ }^{5}$ The working class is seen as not valuing the importance of education vis-à-vis the middle class. However, what 'valuing the importance of education' exactly means by those holding this view is not always clear. At least, they do not make it clear what they refer to are the intrinsic or instrumental values of education.

6 In fact, it is also argued that there are class differences in the ways in which parents and their children respond to and take advantage of new educational policies (e.g. Ball 2006).

7 Recently attention is also directed to parents' emotional resources (e.g. Allatt and Yeandle 1990; Reay 1998).

8 This study was funded in the form of J.K. Swire Memorial Scholarship 1995-1998.

${ }^{9}$ Nine spouses declined to be interviewed. For the sake of convenience, I shall refer the spouse of teacher as $(\mathrm{S} / \mathrm{T})$ and that of manager $(\mathrm{S} / \mathrm{M})$.

10 I sent recruitment letters to a number of big firms, banks, organisations, secondary schools, tertiary institutions, and universities. Three respondents responded to my letter and called me up to arrange for interviews.

11 My parents were keen to help, but they did not know many middle-class people either; yet my father still exhausted his social networks for this research project and introduced me to some of his acquaintances he met many years ago, whom I later interviewed.

12 Recruitment of interviewees was ongoing during the whole period of fieldwork.

13 Statistics on the employment and educational attainment of the population reported below are from Hong Kong Census Statistics Department.

${ }^{14}$ All names in this paper are fictitious.

${ }^{15}$ Every year on the day of releasing the results of POAS, journalists report on how parents made strategic 'moves' the year before their application: buying an expensive apartment in those catchment areas. This year is no exception (e.g. Mingpao 3 June 2007:

http://www.mingpaonews.com/20070603/gsm2.htm).

${ }^{16}$ The syllabus of each subject for HKCEE is covered in secondary form four and five.

17 The syllabus of each subject for HKALE is covered in secondary form six and seven.

18 It is more so the case since the 2000 education reform. One of its goals is to change one-sided emphasis on academic performance to a more balanced emphasis on both academic results and performances in sports and music. This has made a lot of parents send their children to learn swimming, to participate in ball games, and to learn to play different musical instruments (e.g. Mingpao 13 June 2007: http://www.mingpaonews.com/20070613/gfa1.htm).

${ }^{19}$ An increasing number of children over the last few years sitting the examination awarded by the Hong Kong Royal Music Society is reported and discussed in the editorial section of Mingpao 2 April 2007 (http://www.mingpaonews.com/20070402/faa1.htm).

20 It is the official language used in China.

21 Secondary form three students are asked to choose arts or sciences or commercial subjects for secondary form four. But whether they can take the stream of their choice depends on their academic rank in secondary form three.

22 For respondents' children who were aged fifteen or above, I interviewed ten of them.

${ }^{23}$ The evidence on some respondents of a working-class origin not reported for this paper (Wong 2005) 


\section{Acknowledgements}

This article was a result of reworking data collected for a study with which I earned my doctoral at Oxford. I am most grateful to John Goldthorpe and Gordon Marshall for supervising the study. I would like to thank the Center of the Study of Social Stratification and Inequality (CSSI) for providing me with support of all kinds: this is crucial to making this paper possible. And I would also like to thank the Editors and two anonymous referees of Sociological Research Online for their very constructive comments and suggestions on an earlier version of this article.

\section{References}

ALLATT, P. And Yeandle, S. 1990 Youth Unemployment and the Family, London: Routledge.

BALL, S. 2006 Education Policy and Social Class: the selected works of Stephen J. Ball, London and New York: Routledge.

BALL, S. 2003 Class Strategies and the Educational Market: The Middle Classes and Social Advantage, London: RoutledgeFalmer.

BALL, S., Maguire, M., and Macrae, S. 2000 Choice, Pathways and Transitions Post-16: New youth, new economies in the global city, London: RoutlegdeFalmer.

BERNSTEIN, B. 1993 The Structuring of Pedagogic Discourse: Class, codes and control, Reprinted Edition, London and New York: Routledge.

BOTTERO, W. 2003 Stratification: Social division and inequality, London: Routledge.

BOUDON, R. 1974 Education, Opportunity and Social Inequality, New York: Wiley.

BOURDIEU, P. and Passeron, J. 1977 Reproduction: In Education, Society and Culture (Translated by Richard Nice), London: Sage.

BRAY, M. and Kwok, P. 2003 'Demand for private supplementary tutoring: conceptual considerations, and socio-economic patterns in Hong Kong' Economics of Education Review 22(6):611-620.

BREEN, R. and Goldthorpe, J.H. 1997 'Explaining Educational Differentials: Towards a Formal Rational Action Theory' Rationality and Society 9(3):275-305.

BROWN, P. and Scase, R. 1994 Higher Education and Corporate Realities: Class, Culture and the Decline of Graduate Careers, London: UCL Press.

BULTER, T. and Robson, G. 2003 'Plotting the Middle Classes: Gentrification and Circuits of Education in London' Housing Studies 18(1):5-28.

CHAN, K.W. 1991 The making of Hong Kong society: three studies of class formation in early Hong Kong, Oxford: Clarendon Press.

CHAN, T.W. 1994 Social Mobility in Hong Kong, Oxford: D.Phil. Thesis, Nuffield College, University of Oxford.

COLEMAN, J.S. 1988 'Social Capital in the Creation of Human Capital' American Journal of Sociology 94:S95-S120.

CROMPTON, R. 1998 Class and Stratification: An Introduction to Current Debates, Second Edition, Cambridge: Polity Press.

DEVINE, F. 2004 Class Practices: How Parents Help Their Children Get Good Jobs, Cambridge: Cambridge University Press.

DEVINE, F. 1998 'Class Analysis and the Stability of Class Relations' Sociology 32(1):23-42.

DEVINE, F. and Savage, M. 2000 'Conclusion: renewing class analysis' in R. Crompton, F. Devine, M. Savage, and J. Scott (eds) Renewing Class Analysis, Oxford: Blackwell.

ELDER, G.H. 1981 'History and the Life Course' in D. Bertaux (ed) Biography and Society: The Life History Approach in the Social Sciences, Beverly Hill, Calif.: Sage Publications.

ERIKSON, R. and Goldthorpe, J.H. 1992 The Constant Flux: A Study of Class Mobility in Industrial Societies, Oxford: Oxford University Press.

FISCHER, C.S., Hout, M., Jankowski, M.S., Lucas, S.R., Swidler, A. and Voss, K. 1996 Inequality by Design, Princeton, NJ: Princeton University Press. 
FOSTER, P., Hammersley, M. and Gomm, R. 1996 Constructing educational inequality: an assessment of research on school processes, London: Falmer Press.

GOLDTHORPE, J.H. 2000 On Sociology: Numbers, Narratives, and the Integration of Research and Theory, Oxford: Oxford University Press.

GOLDTHORPE, J.H. and McKnight, A. 2006 'The Economic Basis of Social Class' in S.L. Morgan, D.B. Grusky, and G.S. Fields (eds) Mobility and Inequality: Frontiers of Research in Sociology and Economics, Stanford, Calif.: Stanford University Press.

HALSEY, A.H., Heath, A.F. and Ridge, J.M. 1980 Origins and Destinations: Family, Class and Education in Modern Britain, Oxford: Clarendon Press.

HAMBRO, E. 1955 The Problems of Chinese Refugees in Hong Kong, Holland: Sijthoff.

HERRNSTEIN, R.J. and Murray, C. 1994 The Bell Curve, New York: The Free Press.

HIRSCH, F. 1995 Social Limits to Growth, London: Routledge.

HONG KONG 1981: A Review of 1980, Hong Kong Government Publications Bureau, Hong Kong: Hong Kong Government Press.

HONG KONG CENSUS STATISTICS DEPARTMENT, Hong Kong: Hong Kong Government Press.

- Hong Kong Statistics 1947-1967

- Hong Kong 1961 Population Census Main Report

- Hong Kong 1971 Population Census Main Report

- Hong Kong 1976 By-Census Summary Results

- HONG KONG 1981 Population Census Main Report

- Hong Kong 1986 By-Census Summary Results.

- Hong Kong 1991 Population Census Main Report.

- Hong Kong 1996 By-Census Summary Results.

KOHN, M.L. 1977 Class and Conformity: A Study in Values, Second Edition, Chicago: University of Chicago Press.

LAREAU, A. 2000 Home Advantages: Social Class and Parental Intervention in Elementary Education, Lanham, MD: Rowman and Littlefield.

LEWIS, O. 1959 Five Families: Mexican Case Studies in the Culture of Poverty, New York: Basic Books.

LUI, T.L. 1998 'Characteristics of the new middle class in Hong Kong and their future' in T.L. Lui and T. Wong (eds) Class Analysis and Hong Kong, Hong Kong: Ching Man Bookstore (in Chinese).

LYNCH, K. and Moran, M. 2006 'Markets, schools and the convertibility of economic capital: the complex dynamics of class choice' British Journal of Sociology of Education 27(2):221-235.

MARE, R.D. and Chang, H-C. 2006 'Family Attainment Norms and Educational Stratification in the United States and Taiwan: The Effects of Parents' School Transition' in S.L. Morgan, D.B. Grusky, and G.S. Fields (eds) Mobility and Inequality: Frontiers of Research in Sociology and Economics, Stanford, Calif.: Stanford University Press.

MARSHALL, G., Swift, A. and Roberts, S. 1997 Against the Odds, Oxford: Clarendon Press.

MINGPAO (a local newspaper: http://mingpaonews.com), the following three clippings:

http://www.mingpaonews.com/20070402/faa1.htm (2 April 2007)

http://www.mingpaonews.com/20070603/gsm2.htm(3 June 2007)

http://www.mingpaonews.com/20070613/gfa1.htm (13 June 2007)

MOORE, R. 2004 Education and Society: Issues and Explanations in the Sociology of Education, Cambridge: Polity.

MORGAN, S.L., Grusky, D.B. and Fields, G.S. (eds) 2006 Mobility and Inequality: Frontiers of Research in Sociology and Economics, Stanford, Calif.: Stanford University Press.

MORRIS, P., McClelland, J.A.G., and Yeung, T.M. 1994 'Higher Education in Hong Kong: the context of the rationale for rapid expansion' Higher Education 27:125-140.

NASH, R. 2006 'Controlling for "ability": a conceptual and empirical study of primary and secondary effects' 
POST, D. 1994 'Educational Stratification, School Expansion, and Public Policy in Hong Kong' Sociology of Education 67(April):121-138.

POST, D. 1993 'Focus on Educational Attainment: Educational Attainment and the Role of the State in Hong Kong' Comparative Education Review 37(3):240-262.

POWER, S., Edwards, T., Whitty, G. and Wigfall, V. 2003 Education and the Middle Class, Buckingham: Open University Press.

RAFTERY, A.E. and Hout, M. 1993 'Maximally Maintained Inequality: Expansion, Reform, and Opportunity in Irish Education, 1921-75' Sociology of Education 66(1):41-62.

REAY, D. 1998 Class Work, London: University College London Press.

REAY, D., Davies, J., David, M. and Ball, S. 2001 'Choices of Degree or Degrees of Choice? Class, "Race" and the Higher Education Choice Process' Sociology 35(4):855-874.

SAUNDERS, P. 2002 'Reflections on the meritocracy debate in Britain: a response to Richard Breen and John Goldthorpe' British Journal of Sociology 53(4):559-74.

SAUNDERS, P. 1995 'Might Britain be a meritocracy?' Sociology 29(1):29-41.

SAVAGE, M. 2000 Class Analysis and Social Transformation, Buckingham: Open University Press.

SAVAGE, M. and Egerton, M. 1997 'Social Mobility, Individual Ability and the Inheritance of Class Inequality' Sociology 31(4):645-672.

SCHIFF, M. and Lewontin, R. 1986 Education and Class: the irrelevance of IQ genetic studies, Oxford: Clarendon Press.

SCHOFER, E. and Meyer, J.W. 2005 'The Worldwide Expansion of Higher Education in the Twentieth Century' American Sociological Review 70(December):898-920.

SHAVIT, Y. and Blossfeld, H. (eds) 1993 Persistent Inequality: Changing Educational Attainment in Thirteen Countries, Oxford: Westview Press.

SKEGGS, B. 1997 Formations of Class and Gender, London: Sage.

SWEETING, A. 2004 Education in Hong Kong, 1941 to 2001: Visions and Revisions, Hong Kong: Hong Kong University Press.

THUROW, L.C. 1972 ‘Education and Economic Inequality’ The Public Interest 28(1):66-81.

TREIMAN, D.J. and Yip, K. 1989 'Educational and Occupational Attainment in 21 Countries' in M.L. Kohn (ed) Cross-national Research in Sociology, Newbury Park: Sage.

WATERS, J.L. 2006 'Emergent Geographies of International Education and Social Exclusion' Antipode 38(5):1046-1068.

WILLIS, P. 1977 Learning to Labour: how working class kids get working class jobs, Farnborough: Saxon House.

WONG, Yi-Lee, 2005 'Class and the Educational Attainment of Siblings: An explanatory Model for Social Mobility' Research in Social Stratification and Mobility, Volume 23, Chapter 5: 129-151.

WONG, Yi-Lee, 2004 'A Unified Middle Class or Two Middle Classes? A Comparison of Career Strategies and Intergenerational Mobility Strategies between Teachers and Managers in contemporary Hong Kong', British Journal of Sociology 55 (2): 167-186. 